\title{
Compressed Air Energy Storage for a Small-Scale Wind Turbine
}

\author{
Abdullah Bin Walid', Juliana D'Angela Mariano \\ ${ }^{1}$ New York Institute of Technology \\ Vancouver, BC, Canada \\ awalid@nyit.edu; jmariano@nyit.edu \\ ${ }^{2}$ New York Institute of Technology \\ Vancouver, BC, Canada
}

\section{Extended Abstract}

Wind energy is one of the leading renewable energy sources. However, the intermittent nature of wind means that reliable and continuous output from wind turbines is unpredictable. An energy storage system such as batteries can be an effective way to provide energy during fluctuating output and demands. This paper aims to examine such an energy storage technology called compressed air energy storage (CAES) system for a small-scale wind turbine.

Small-scale wind turbines $(<5-10 \mathrm{~kW})$ using a battery bank for energy storage may not be economically feasible considering the high cost of AC to DC rectifiers and batteries. One way of storing energy is using compressed air. A compressed air energy storage (CAES) system can be implemented with wind turbines to store energy from off-peak periods and then utilized during power fluctuations.

An air compressor is used to compress air and then stored in a storage tank. Air compression can be done adiabatically or near isothermally. The compressed air is then passed through a scroll expander coupled with a clutch or a Pelton wheel. The expander's rotational energy is utilized to provide the necessary torque for the wind turbine drivetrain and the generator [1]. The CAES system is coupled with a control system to provide necessary torque during fluctuating wind speed and generate more stable output. In high demand during low wind speed, the expander can operate for a short period and provide torque for the sudden increase in power demand. Such a system can also reach the desired torque requirement quickly in case of a quick start-up. The compressed air can also be used to provide emergency braking for the system.

In this paper, a $1 \mathrm{~kW}$ wind turbine system is examined. With a $\mathrm{CP}$ of 0.35 and a $95 \%$ efficiency generator, the generator power input is $1052 \mathrm{~W}$. The required torque is $5.58 \mathrm{Nm}$ for the $1800 \mathrm{rpm}$ generator. The storage system is designed to provide energy for 30 minutes. The reason is that the CAES system's primary function is to store energy for stabilizing the power fluctuations and provide a short-term boost of power. The total required energy for this purpose is $1.90 \mathrm{MJ}$. The system operates under $1 \mathrm{~atm}$ pressure, and this results in a volume change of $18.70 \mathrm{~m}^{3}$. A 3 m radius and $3 \mathrm{~m}$ long cylindrical storage unit can provide the necessary work requirement (the displacement $\mathrm{dV}$ is $2.64 \mathrm{~m}$ ). The CAES system is not designed to provide energy when there is no wind. The system is designed to provide energy to stabilize the rated output (1kW) and for sudden power demands. So, if the system will provide $33 \%$ of the required energy when the turbine is below rated power, the storage tank dimensions are even smaller. The PdV work becomes $0.62 \mathrm{MJ}$, and the displacement volume is $6.12 \mathrm{~m}^{3}$. A $1 \mathrm{~m}$ radius and $2 \mathrm{~m}$ length cylinder can store this energy.

\section{References}

[1] H. Sun, X. Luo, J. Wang, "Feasibility study of a hybrid wind turbine system - Integration with compressed air energy storage," Applied Energy, vol. 137, pp. 617-628, 2015. 